\title{
Sterol Regulatory Element Binding Protein 2 Overexpression Is Associated With Reduced Adipogenesis and Ectopic Fat Accumulation in Transgenic Spontaneously Hypertensive Rats
}

\author{
V. LANDA ${ }^{1}$, V. ZÍDEK ${ }^{1}$, P. MLEJNEK ${ }^{1}$, M. ŠIMÁKOVÁ ${ }^{1}$, J. ŠILHAVÝ $^{1}$, J. TRNOVSKÁ ${ }^{2,3}$, \\ L. KAZDOVÁ ${ }^{2}$, M. PRAVENEC ${ }^{1}$ \\ ${ }^{1}$ Institute of Physiology, Academy of Sciences of the Czech Republic, Prague, Czech Republic, \\ ${ }^{2}$ Center for Experimental Medicine, Institute for Clinical and Experimental Medicine, Prague, \\ Czech Republic, ${ }^{3}$ Czech University of Life Sciences, Faculty of Agrobiology, Food and Natural \\ Resources, Department of Veterinary Sciences, Prague, Czech Republic
}

Received February 12, 2014

Accepted March 21, 2014

On-line June 5, 2014

\section{Summary}

It has been reported that the major function of the sterol regulatory element binding protein 2 (SREBP-2) is to activate preferentially cholesterol biosynthesis in liver and adipose tissue rather than fatty acid synthesis. In the current study, we analyzed the effects of overexpression of human dominantpositive SREBP-2 transgene under control of PEPCK promoter in the spontaneously hypertensive rat (SHR) on lipid and glucose metabolism. Transgenic overexpression of SREBP-2 was associated with significantly higher hepatic triglycerides $(20.4 \pm 0.9$ vs. $17.0 \pm 0.05 \mu \mathrm{mol} / \mathrm{g}, \mathrm{P}<0.05)$ but not cholesterol $(10.6 \pm 0.4$ vs. $10.9 \pm 0.4 \mu \mathrm{mol} / \mathrm{g})$ and decreased relative weight of epididymal fat pad $(0.73 \pm 0.03$ vs. $0.83 \pm 0.03, \mathrm{P}<0.05)$. In addition, muscle triglyceride $(15.8 \pm 3.7$ vs. $8.5 \pm 1.2 \mu \mathrm{mol} / \mathrm{g}$, $\mathrm{P}<0.001)$ and cholesterol $(3.6 \pm 0.5$ vs. $2.1 \pm 0.1 \mu \mathrm{mol} / \mathrm{g}, \mathrm{P}<0.05)$ concentrations were significantly increased in transgenic rats when compared to SHR controls. Ectopic fat accumulation was associated with significantly increased serum glucose levels $(6.4 \pm 0.1$ vs. $5.9 \pm 0.1 \mathrm{mmol} / \mathrm{l}, \mathrm{P}<0.005)$ and reduced insulin levels $(1.78 \pm 0.33$ vs. $2.73 \pm 0.37 \mathrm{nmol} / \mathrm{l}, \mathrm{P}<0.05)$ in transgenic rats. These results provide evidence for important role of SREBP2 in regulation of lipid and glucose metabolism.

\section{Key words}

Sterol regulatory element binding protein 2 - Transgenic • Spontaneously hypertensive rat $\bullet$ Triglycerides $\bullet$ Cholesterol

\section{Corresponding author}

M. Pravenec, Institute of Physiology, Academy of Sciences of the Czech Republic, Vídeňská 1083, 14220 Prague 4, Czech Republic. E-mail: pravenec@biomed.cas.cz

\section{Introduction}

The spontaneously hypertensive rat (SHR) is the most widely used animal model of essential hypertension and under special environmental condition, such as when fed a high sucrose diet, also develops disturbances of lipid and glucose metabolism (Pravenec et al. 2014). Sterol regulatory element binding proteins (SREBPs) belong to a family of transcription factors that play important role in regulation of cholesterol and fatty acid biosynthesis. There are 3 SREBPs that are coded by 2 genes. Srebfl (sterol regulatory binding protein factor 1) codes for 2 isoforms, SREBP-1a and SREBP-1c, by using alternate promoters. The second gene, Srebf2 (sterol regulatory element binding protein 2) codes for SREBP-2 transcription factor (Brown and Goldstein 1997). While all 3 SREBPs activate similar sets of genes they differ in their effects on fatty acid and cholesterol metabolism. The role of these 3 isoforms in regulation of lipid metabolism was tested in mice and rats that expressed dominant-positive SREBP transgenes under control of the PEPCK promoter. Both mice and rats expressing SREBP-1a transgenic isoform exhibited 
extreme hepatic steatosis due to increased triglyceride and cholesterol content and reduced adiposity (Shimano et al. 1996, Qi et al. 2005, Malínská et al. 2010) which suggested that SREBP-1a isoform plays an important role in regulation of both cholesterol and fatty acid synthesis in the liver. On the other hand, mice and rats expressing a dominant-positive SREBP-1c isoform showed only modest increase in hepatic triglycerides and cholesterol (Shimano et al. 1997, Pravenec et al. 2008). Finally, studies with mice expressing dominant-positive SREBP-2 isoform provided evidence that the major role of SREBP2 is to activate cholesterol biosynthesis in preference to fatty acid synthesis in liver and adipose tissue (Horton et al. 1998). In the current study, we analyzed metabolic effects of overexpressing dominant-positive SREBP-2 isoform in the spontaneously hypertensive rat (SHR). We found that expression of the dominant-positive SREBP-2 is associated with increased hepatic triglycerides but not cholesterol, reduced adipogenesis, and with ectopic fat accumulation in muscles in the SHR.

\section{Methods}

\section{Generation of transgenic rats}

Transgenic rats overexpressing dominantpositive form of human SREBP-2 were derived on genetic background of the SHR/Ola strain. Transgenic SHR were produced by microinjection of ova with a cDNA construct encoding amino acids 1 to 468 of human SREBP-2 under control of the rat PEPCK (phosphoenolpyruvate carboxykinase) promoter, which produces high levels of gene expression in the liver (SREBP-2 construct was kindly provided by J. Horton and J. Goldstein). The cDNA transgene generates a truncated form of SREBP-2 that can enter the nucleus without proteolysis and is not subject to feedback regulation (Horton et al. 1998). The rats were housed in an air-conditioned animal facility and allowed free access to food and water. We used males ( $N=8$ per group) at the age of 4 months. Rats were fed a standard chow till 14 weeks of age and 2 weeks prior to experiment a diet containing $60 \%$ fructose. A high fructose diet was used in these studies based on previous work indicating that such diets facilitate the development of metabolic disturbances in SHR models (Pravenec et al. 2014). All protocols were performed in agreement with the Animal Protection Law of the Czech Republic and were approved by the Ethics Committee of the Institute of Physiology, Academy of Sciences of the Czech Republic.
Expression analysis of transgenic and endogenous SREBP-2 genes

Real-time PCR analysis was used to detect expression of the human SREBP-2 transgene. For realtime PCR, total RNA was isolated using standard methods and cDNA was prepared and analyzed by realtime PCR testing using QuantiTect SYBR Green reagents (Qiagen, Inc, Valencia, U.S.A.) on an Opticon continuous fluorescence detector (MJ Research, Waltham, U.S.A.). Gene expression levels were normalized relative to the expression of cyclophilin (peptidylprolyl isomerase A), which served as the internal control, with results being determined in triplicate. Expression of the transgene encoding human SREBP-2 was quantified using the following primers: upstream, 5'-GAG ACC ATG GAG ACC CTC AC; downstream, 5'-CAG GGA ACT CTC CCA CTT GA. Expression of endogenous gene encoding rat SREBP-2 was quantified using the following primers: upstream, 5'-ATC ATC CAG CAG CCT TTG AT; downstream, 5'-CTG TAC CTG CGA GGA TGT CA.

\section{Tissue triglyceride measurements}

For determination of triglycerides in liver and soleus muscle, tissues were powdered under liquid $\mathrm{N}_{2}$ and extracted for $16 \mathrm{~h}$ in chloroform:methanol, after which $2 \% \mathrm{KH}_{2} \mathrm{PO}_{4}$ was added and the solution was centrifuged. The organic phase was removed and evaporated under $\mathrm{N}_{2}$. The resulting pellet was dissolved in isopropyl alcohol, and triglyceride content was determined by enzymatic assay (Erba-Lachema, Brno, Czech Republic).

\section{Biochemical analyses}

Biochemical parameters were measured in blood samples drawn from non-fasting rats. Blood glucose levels were measured by the glucose oxidase assay (ErbaLachema, Brno, Czech Republic) using tail vein blood drawn into $5 \%$ trichloracetic acid and promptly centrifuged. NEFA levels were determined using an acylCoA oxidase-based colorimetric kit (Roche Diagnostics $\mathrm{GmbH}$, Mannheim, Germany). Serum triglyceride and cholesterol concentrations were measured by standard enzymatic methods (Erba-Lachema, Brno, Czech Republic). Serum insulin concentrations were determined using the Mercodia Rat Insulin ELISA kit (Mercodia AB, Uppsala, Sweden).

\section{Oral glucose tolerance testing}

Oral glucose tolerance tests were performed using a glucose load of $300 \mathrm{mg} / 100 \mathrm{~g}$ body weight after 
overnight fasting. Blood was drawn from the tail without anesthesia before the glucose load ( 0 min time point) and at 30,60 , and $120 \mathrm{~min}$ thereafter.

\section{Statistical analysis}

We performed the statistical analysis using ttests or rank sum tests for two group comparisons. All results are expressed as means \pm standard errors of the means (SEM).

\section{Results}

Expression of the human SREBP-2 transgene and Srebf 2 endogenous gene

Real-time PCR analysis confirmed abundant hepatic expression of the human transgene encoding SREBP-2 compared with expression of the endogenous Srebf2 gene (Fig. 1). Lower expression of the transgene and Srebf 2 endogenous gene was detected also in adipose tissue.

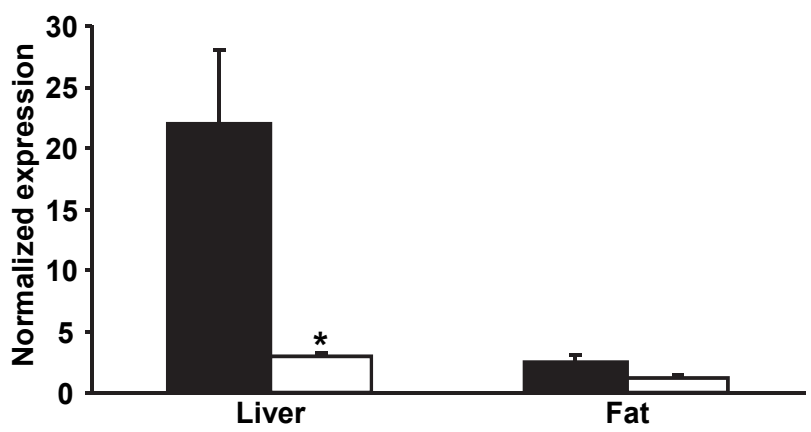

Fig. 1. Gene expression levels. Real-time PCR analysis of SHR transgenic rats showing tissue expression levels of the transgene for SREBP-2 (solid bars) compared with expression levels of the endogenous gene for SREBP-2 (open bars) in liver and adipose tissue. * denotes $\mathrm{P}<0.05$.

\section{Metabolic effects of transgenic expression of SREBP-2}

As can be seen in Table 1, transgenic rats when compared to nontransgenic controls, had significantly higher body weight but lower weight of relative epididymal fat pad. Serum triglycerides were increased in transgenic rats while no significant differences were found in serum NEFA and cholesterol. Transgenic rats had higher hepatic triglyceride but not cholesterol concentrations versus SHR controls. On the other hand, muscle triglycerides and cholesterol were increased in transgenic rats which was associated with significantly higher glucose and reduced insulin levels. In addition, transgenic rats had higher levels of NEFA during OGTT which suggests reduced antilipolytic action of insulin (Table 1). No significant differences were observed in serum glucose or insulin concentrations during OGTT (data not shown).

Table 1. Metabolic phenotypes in SHR-Srebf2 transgenic versus SHR controls.

\begin{tabular}{|c|c|c|}
\hline Trait & SHR-Srebf2 & SHR \\
\hline Body weight (g) & $327 \pm 7$ & $304 \pm 6 *$ \\
\hline $\begin{array}{l}\text { Rel. epididymal fat } \\
\text { weight }(\mathrm{g} / 100 \mathrm{~g} \mathrm{BW})\end{array}$ & $0.73 \pm 0.03$ & $0.83 \pm 0.03 *$ \\
\hline $\begin{array}{l}\text { Serum triglycerides } \\
\text { (mmol/l) }\end{array}$ & $2.10 \pm 0.10$ & $1.40 \pm 0.08 *$ \\
\hline $\begin{array}{l}\text { Serum NEFA } \\
(\mathrm{mmol} / \mathrm{l})\end{array}$ & $0.57 \pm 0.06$ & $0.64 \pm 0.09$ \\
\hline $\begin{array}{l}\text { Serum NEFA during } \\
\text { OGTT (mmol/l) }\end{array}$ & $0.81 \pm 0.03$ & $0.59 \pm 0.04 *$ \\
\hline $\begin{array}{l}\text { Serum glucose } \\
(\mathrm{mmol} / \mathrm{l})\end{array}$ & $6.4 \pm 0.1$ & $5.9 \pm 0.1^{* *}$ \\
\hline $\begin{array}{l}\text { Serum insulin } \\
(\mathrm{nmol} / \mathrm{l})\end{array}$ & $1.8 \pm 0.3$ & $2.7 \pm 0.4^{*}$ \\
\hline $\begin{array}{l}\text { Serum cholesterol } \\
\text { (mmol/l) }\end{array}$ & $1.6 \pm 0.1$ & $1.7 \pm 0.1$ \\
\hline $\begin{array}{l}\text { Liver triglycerides } \\
(\mu \mathrm{mol} / \mathrm{g})\end{array}$ & $20.4 \pm 0.9$ & $17.0 \pm 0.5^{*}$ \\
\hline $\begin{array}{l}\text { Liver cholesterol } \\
(\mu \mathrm{mol} / \mathrm{g})\end{array}$ & $10.6 \pm 0.4$ & $10.9 \pm 0.4$ \\
\hline 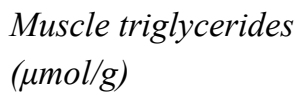 & $14.1 \pm 1.5$ & $9.4 \pm 1.4^{*}$ \\
\hline $\begin{array}{l}\text { Muscle cholesterol } \\
(\mu \mathrm{mol} / \mathrm{g})\end{array}$ & $3.6 \pm 0.5$ & $2.1 \pm 0.1 *$ \\
\hline
\end{tabular}

* and ** denote $\mathrm{P}<0.05$ and $\mathrm{P}<0.005$, respectively.

\section{Discussion}

In our previous studies with SREBP-1a and SREBP-1c dominant-positive transgenes expressed on genetic background of the spontaneously hypertensive rat (SHR), we observed significant effects on lipid and glucose metabolism. Overexpression of SREBP-1a isoform was associated with striking accumulation of triglycerides in the liver, oxidative stress, and steatohepatitis (Qi et al. 2005, Malínská et al. 2010). On the other hand, overexpression of the SREBP-1c isoform in the SHR, which harbors a mutant form of the Srebf1 gene that predisposes the SHR to hepatic steatosis, was 
used for a transgenic rescue experiment (Pravenec et al. 2008). In the current study, we analyzed metabolic effects associated with overexpression of the dominant-positive SREBP-2 transgene. SREBP-2 transgenic rats when compared to nontransgenic controls exhibited significantly increased hepatic levels of triglycerides but not cholesterol, lower adiposity, and increased triglyceride and cholesterol content in muscles. Ectopic fat accumulation in livers and muscles was associated with increased levels of nonfasting glucose and reduced insulin. Although we did not measure lipid content in pancreatic $\beta$-cell cell it is possible that ectopic fat accumulation in pancreas leads to dysregulated insulin secretion (Kazdová et al. 2002).

Contrary to mice that overexpressed the same dominant-positive SREBP-2 transgene (Horton et al. 1998), we observed no increase in hepatic cholesterol levels which does not support the major role of SREBP-2 in cholesterol synthesis in the liver. In addition, we observed reduced adiposity in transgenic rats associated with ectopic fat accumulation and insulin resistance. Such discrepant results might be explained by different genetic backgrounds (rats versus mice) and different diets (high fructose versus high protein/low carbohydrate). It can be concluded that overexpression of SREBP-2 in the SHR fed a high fructose diet is associated with reduced white adipose tissue mass and ectopic fat accumulation in livers and muscles but not with significant differences in cholesterol content in tissues.

\section{Conflict of Interest}

There is no conflict of interest.

\section{Acknowledgements}

This work was supported by grant LH12061 from Ministry of Education, Youth, and Sports of the Czech Republic to V.L.

\section{References}

BROWN MS, GOLDSTEIN JL: The SREBP pathway: regulation of cholesterol metabolism by proteolysis of a membrane-bound transcription factor. Cell 89: 331-340, 1997.

HORTON JD, SHIMOMURA I, BROWN MS, HAMMER RE, GOLDSTEIN JL, SHIMANO H: Activation of cholesterol synthesis in preference to fatty acid synthesis in liver and adipose tissue of transgenic mice overproducing sterol regulatory element-binding protein-2. J Clin Invest 101: 2331-2339, 1998.

KAZDOVÁ L, DIVIŠOVÁ J, CAHOVÁ M, MARKOVÁ I: Aging-induced impairment of insulin secretion is associated with increased islet triglyceride content in non-obese hereditary hypertriglyceridemic rats. Diabetologia 45 (Suppl 2): 228, 2002.

MALÍNSKÁ H, OLIYARNYK O, HUBOVÁ M, ZÍDEK V, LANDA V, SIMÁKOVÁ M, MLEJNEK P, KAZDOVÁ L, KURTZ TW, PRAVENEC M: Increased liver oxidative stress and altered PUFA metabolism precede development of non-alcoholic steatohepatitis in SREBP-1a transgenic spontaneously hypertensive rats with genetic predisposition to hepatic steatosis. Mol Cell Biochem 335: 119-125, 2010.

PRAVENEC M, KAZDOVÁ L, LANDA V, ZÍDEK V, MLEJNEK P, ŠIMÁKOVÁ M, JANSA P, FOREJT J, KŘEN V, KŘENOVÁ D, QI N, WANG JM, CHAN D, AITMAN TJ, KURTZ TW: Identification of mutated Srebf1 as a QTL influencing risk for hepatic steatosis in the spontaneously hypertensive rat. Hypertension 51: 148$153,2008$.

PRAVENEC M, KŘEN V, LANDA V, MLEJNEK P, MUSILOVÁ A, ŠILHAVÝ J, ŠIMÁKOVÁ M, ZÍDEK V: Recent progress in the genetics of spontaneously hypertensive rats. Physiol Res 63 (Suppl 1): S1-S8, 2014.

QI NR, WANG J, ZÍDEK V, LANDA V, MLEJNEK P, KAZDOVÁ L, PRAVENEC M, KURTZ TW: A new transgenic rat model of hepatic steatosis and the metabolic syndrome. Hypertension 45: 1004-1011, 2005.

SHIMANO H, HORTON JD, HAMMER RE, SHIMOMURA I, BROWN MS, GOLDSTEIN JL: Overproduction of cholesterol and fatty acids causes massive liver enlargement in transgenic mice expressing truncated SREBP1a. J Clin Invest 98: 1575-1584, 1996.

SHIMANO H, HORTON JD, SHIMOMURA I, HAMMER RE, BROWN MS, GOLDSTEIN JL: Isoform 1c of sterol regulatory element binding protein is less active than isoform 1a in livers of transgenic mice and in cultured cells. J Clin Invest 99: 846-854, 1997. 